\title{
Influência dos Parâmetros Dimensionais da Pilha na Qualidade da Madeira de Eucalyptus spp. Submetida à Secagem ao Ar
}

\author{
Osmar Andrei Liebl ${ }^{1}$, Pedro Lício Loiola ${ }^{1}$, Linéia Roberta Zen ${ }^{1}$, \\ Ricardo Jorge Klitzke ${ }^{1}$, Márcio Pereira da Rocha ${ }^{1}$
}

${ }^{1}$ Departamento de Engenharia e Tecnologia Florestal, Universidade Federal do Paraná - UFPR, Curitiba/PR, Brasil

\begin{abstract}
RESUMO
Este trabalho teve como objetivo avaliar a influência da largura da pilha de madeira e da espessura dos separadores na velocidade de secagem, nos defeitos gerados e da distribuição de umidade na madeira de Eucalyptus spp. Foram testadas duas larguras de pilhas (1.800 e $900 \mathrm{~mm}$ ), ambas com $3.000 \mathrm{~mm}$ de comprimento, construídas com separadores de 20 e $25 \mathrm{~mm}$ de espessura. Foram avaliados a velocidade de secagem, a distribuição da umidade final e os principais defeitos gerados após 90 dias de secagem ao ar. A redução da largura da pilha ocasionou um aumento da velocidade de secagem, sendo o resultado mais satisfatório para a pilha confeccionada com separador de $25 \mathrm{~mm}$ de espessura. Para a qualidade da madeira de Eucalyptus spp. após a secagem ao ar, houve influência da redução da largura da pilha, a qual reduziu a umidade final das tábuas e a variação de umidade entre as tábuas, e os defeitos gerados foram inferiores aos limites estabelecidos pela norma.
\end{abstract}

Palavras-chave: pilha de madeira, taxa de secagem, umidade final, defeitos de secagem.

\section{Influence of Wood Stack Dimensional Parameters in Quality of Eucalyptus spp. Submitted to Air Drying}

\begin{abstract}
This study aimed to evaluate the influence of the width of the sawn timber stack and thickness of the stickers in the drying velocity, the generated defects and moisture distribution within the stack in Eucalyptus spp.. Two widths of stacks were tested (1800 and $900 \mathrm{~mm}$ ), both $3000 \mathrm{~mm}$ long, constructed with 20 and $25 \mathrm{~mm}$ thick stickers. We evaluated the drying rate, final moisture in distribution and main defects generated after 90 days of air drying. Reducing the width of the stack caused an increase in drying velocity, the most satisfactory results for the timber stack made with $25 \mathrm{~mm}$ thickness. The reduction of the wood stack width influenced the quality of Eucalyptus spp. after air drying, showing a decrease of the final moisture of the lumber boards. The moisture variation between the boards and the defects generated were below the limits set by default.
\end{abstract}

Keywords: timber stacks, drying rate, final moisture, defects drying. 


\section{INTRODUÇÃO}

Atualmente, a utilização do gênero Eucalyptus spp. deixou de ser uma matéria-prima alternativa para a indústria madeireira, tornando-se uma realidade para o setor industrial de produtos sólidos de madeira. Entretanto, existe a necessidade de adequação dos processos de beneficiamento da madeira, pois a utilização do gênero implica o processamento de árvores jovens e diâmetros reduzidos (Paes et al., 2015).

O processamento desse tipo de lenho está relacionado a perdas em toda a cadeia produtiva, que vão desde a operação de colheita das árvores até a fase final de processamento, incluindo as fases de usinagem e acabamentos. Klitzke (2007) afirma que o processo de secagem da madeira, quando não conduzido de forma adequada, gera perdas significativas de material, ocasionadas por defeitos como rachaduras, empenamentos e colapso. A ineficácia do processo de secagem se deve à rápida perda da umidade superficial e à lenta translocação da umidade interna para a superfície. A velocidade da secagem está diretamente relacionada ao tipo de madeira, dimensões e arranjo das pilhas no pátio de secagem.

$\mathrm{Na}$ secagem natural, para a maioria das espécies, ocorre perda da metade de umidade nos primeiros 30 dias, sendo o restante eliminado a um tempo de três a cinco vezes maior, permanecendo a madeira sob as mesmas condições de exposição (Stangerlin et al., 2009). O principal objetivo da secagem ao ar é fazer com que a maior quantidade possível de água evapore, utilizando-se as forças da natureza, tendo os custos industriais reduzidos. Esse tipo de secagem é utilizado muitas vezes como pré-secagem ou secagem parcial, sendo a fase final feita em estufas, como também para secagem completa, dependendo do seu uso (Ponce \& Watai, 1985). Batista et al. (2013) ainda complementam que a secagem ao ar, além de reduzir o tempo necessário para a posterior secagem artificial, também pode reduzir a incidência de defeitos normalmente observados nas fases iniciais do processo.

Como alternativa para reduzir o tempo de permanência da madeira em câmara convencional, diversos autores (Stöhr, 1977; Campbell \& Hartley, 1988; Northway, 1996) têm sugerido, como métodos aplicáveis à madeira do gênero Eucalyptus, o uso da pré-secagem ou a combinação da secagem ao ar com posterior secagem convencional. Essa combinação proporcionaria redução de custos e otimização do processo, com maior operacionalidade dos secadores.

O grande desafio é buscar alternativas de processos e de técnicas que sejam economicamente viáveis, que permitam a obtenção de madeira seca com as características de qualidade exigidas pelo mercado no menor tempo possível, com redução nos custos de processamento.

Em função dessa necessidade, este trabalho teve como objetivo avaliar a influência da largura da pilha de madeira e a espessura dos sarrafos separadores (tabiques) na qualidade da madeira em termos de distribuição de umidade na pilha, na velocidade de secagem e na incidência dos defeitos, como rachaduras e empenamentos.

\section{MATERIAL E MÉTODOS}

\subsection{Preparação do material para secagem}

O trabalho foi desenvolvido com a empresa Artsoli Móveis Ltda., localizada no Município de Mafra, em Santa Catarina (SC), especializada na produção de salas de jantar para o mercado interno, além de mesas, cadeiras e outros produtos para exportação.

A madeira serrada utilizada no presente estudo foi proveniente de árvores de Eucalyptus spp., com $35 \mathrm{~mm}$ de diâmetro, tendo aproximadamente 18 anos de idade, procedentes de plantios florestais oriundas de povoamento homogêneo localizado no município de Massaranduba (SC).

As pilhas foram construídas nas dimensões de $1.800 \mathrm{e}$ $900 \mathrm{~mm}$ de largura, ambas com $3.000 \mathrm{~mm}$ de comprimento. $\mathrm{Na}$ construção, foram utilizadas duas espessuras de sarrafos separadores (tabiques), uma com $20 \mathrm{~mm}$ e a outra com $25 \mathrm{~mm}$. A seguir, foram levadas para um pátio de secagem ao ar livre e instaladas sobre piquetes a $200 \mathrm{~mm}$ do solo, levando em consideração a direção predominante do vento, sendo este perpendicular ao comprimento das pilhas.

Para avaliar a influência dos fatores largura das pilhas e espessura dos sarrafos separadores, foram montadas oito pilhas (Tabela 1).

As larguras das pilhas foram escolhidas em função da dimensão das vagonetes que as câmaras de secagem da empresa possuem, sendo normalmente utilizada a 
largura de $1.800 \mathrm{~mm}$. Assim, pode-se testar a melhor combinação entre largura da pilha e espessura dos sarrafos separadores que otimize a capacidade de carga do equipamento.

Após a formação das pilhas, foram selecionadas e preparadas as amostras de controle de forma representativa à carga, segundo a metodologia recomendada por Simpson (1991), as quais, periodicamente, tiveram aferidas suas massas para o controle da perda de umidade da madeira por um período de 90 dias.

\subsection{Velocidade de secagem e variação de umidade na pilha}

A determinação da velocidade de secagem das madeiras de Eucalyptus spp. para as diferentes pilhas montadas foi determinada em função da relação dos intervalos de umidade inicial e final e do tempo em dias decorridos, sendo expressa em porcentagem de umidade por dia $\left(\% \mathrm{U} \cdot \operatorname{dia}^{-1}\right)$, seguindo as recomendações de Simpson (1991).

A determinação das umidades inicial e final da madeira foi obtida pelo método gravimétrico, sendo retiradas de cada pilha amostras de $25 \mathrm{~mm}$ de comprimento, mantendo a espessura e a largura nominais das tábuas. As amostras foram retiradas na posição central de dez tábuas, seguindo a recomendação da Norma Brasileira Regulamentadora (NBR 7.190), da Associação Brasileira de Normas Técnicas (ABNT, 1997).
Para o monitoramento da perda de umidade, as amostras de controle foram dispostas em local de fácil remoção ao longo das pilhas, de modo a permitir uma medição real e representativa de umidade destas. Para tanto, suas massas foram aferidas semanalmente, em balança digital de precisão $0,01 \mathrm{~g}$.

\subsection{Avaliação dos defeitos de secagem}

Para avaliar a incidência de defeitos proporcionados pela pré-secagem da madeira, foram realizadas duas avaliações, constituídas de uma avaliação após o desdobro das toras, seguida de uma segunda avaliação após a pré-secagem. Foram mensurados os seguintes defeitos: rachaduras de topo e empenamentos (arqueamento, encurvamento e encanoamento).

Os empenamentos e rachaduras foram quantificados e classificados conforme recomendações da NBR 14.806 (ABNT, 2002), realizando a classificação de madeiras pré-seca conforme demonstrado na Tabela 2.

\subsection{Análise estatística}

Na comparação dos resultados da influência da largura da pilha de madeira, bem como da espessura dos sarrafos separadores, empregou-se um delineamento inteiramente casualizado, com arranjo fatorial, em que foram analisados os seguintes fatores: largura da pilha de madeira (dois níveis), espessura dos tabiques separadores (dois níveis) e interação entre esses fatores,

Tabela 1. Descrição das pilhas de madeira submetidas à secagem ao ar.

Table 1. Description of timber stack subjected to air drying.

\begin{tabular}{cccc} 
Tratamentos & Largura $(\mathbf{m m})$ & Sarrafo separador $\mathbf{( m m )}$ & Número de pilhas \\
\hline Tratamento 1 & 1800 & 20 & 2 \\
Tratamento 2 & 1800 & 25 & 2 \\
\hline Tratamento 3 & 900 & 20 & 2 \\
Tratamento 4 & 900 & 25 & 2 \\
\hline
\end{tabular}

Tabela 2. Classificação dos empenamentos e rachaduras.

Table 2. Classification of warping and checks.

\begin{tabular}{|c|c|c|c|}
\hline \multirow{2}{*}{ Empenamento (mm) } & \multicolumn{3}{|c|}{ Magnitude } \\
\hline & Leve & Médio & Forte \\
\hline Arqueamento & $a \leq 3$ & $3<a \leq 10$ & $a>10$ \\
\hline Encanoamento & $c \leq 2$ & $2<c \leq 4$ & $c>4$ \\
\hline Encurvamento & $\mathrm{e} \leq 10$ & $10<\mathrm{e} \leq 20$ & $e>20$ \\
\hline \multirow{2}{*}{ Classificação das rachaduras (mm) } & Pequena & Média & Forte \\
\hline & $\mathrm{CR} \leq 50$ & $50<\mathrm{CR} \leq 300$ & $\mathrm{CR}>300$ \\
\hline
\end{tabular}

a: arqueamento; c: encanoamento; e: encurvamento; CR: comprimento da rachadura. Fonte: NBR 14806 (2002). 
e quando significativo, aplicou-se o teste de Tukey de $5 \%$ de probabilidade para a comparação das médias da velocidade de secagem.

\section{RESULTADOS E DISCUSSÃO}

\subsection{Curva e velocidade de secagem}

As pilhas de madeira de Eucalyptus spp. confeccionadas com $1.800 \mathrm{~mm}$ de largura iniciaram o processo de secagem com umidade média de $97,45 \%$ (para ambas as pilhas), finalizando o processo de pré-secagem com valores de umidade de $41,70 \%$ para a pilha que dispunha de separadores (tabiques) de $20 \mathrm{~mm}$ e $35,46 \%$ para a pilha confeccionada com separadores (tabiques) de $25 \mathrm{~mm}$.

As pilhas que foram confeccionadas com $900 \mathrm{~mm}$ de largura tinham umidade média de $128,24 \%$ e 104,75\% (para as pilhas com separadores de 20 e com $25 \mathrm{~mm}$ de espessura, respectivamente), finalizando o processo de pré-secagem com umidade de $20,69 \%$ e $19,97 \%$, respectivamente (Figura 1).
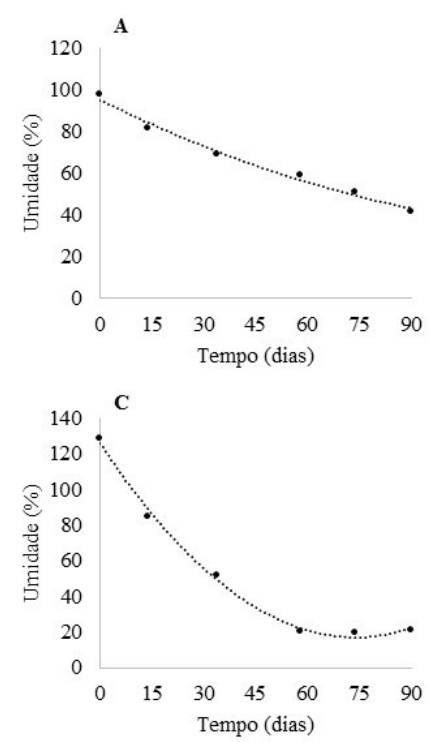

Nota-se que o valor de umidade final da madeira pertencente às pilhas confeccionadas com $1.800 \mathrm{~mm}$ de largura foi superior em 50,38\% e 43,68\% em comparação às pilhas com $900 \mathrm{~mm}$ de largura, respectivamente, confeccionadas com separadores (tabiques) de 20 e $25 \mathrm{~mm}$ de espessura. Tal fato está relacionado à perda de eficiência da transferência de calor e de massa no fluxo de fluido (ar) ao longo da largura das pilhas (1.800 e $900 \mathrm{~mm}$, respectivamente). Outro fator relevante é a capacidade do ar em absorver moléculas de vapor d'água a uma dada temperatura (pressão de vapor saturado) em função da largura da pilha.

A diferença de umidade inicial da madeira ocorreu em função do tempo em que as árvores foram abatidas até o processamento mecânico para confecção das tábuas, iniciando o processo de pré-secagem da madeira. Conforme Bauer (2003), a madeira de Eucalyptus sp. em seu estado verde pode oscilar de $60 \%$ até valores superiores a $130 \%$ de umidade.
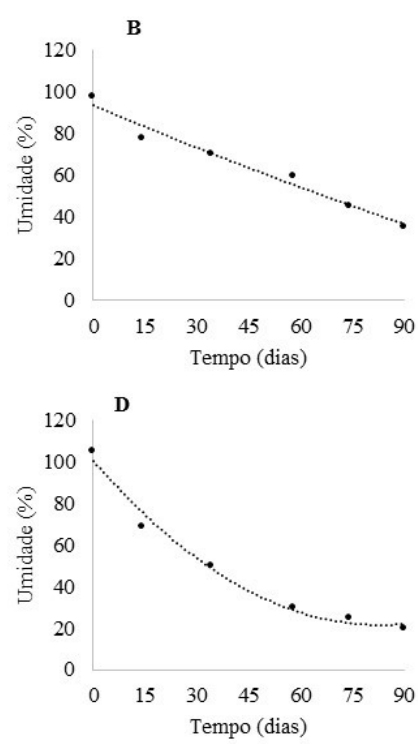

Figura 1. Perda de umidade ao longo dos dias da secagem ao ar da madeira de Eucalyptus spp. para os diferentes tratamentos avaliados. (A) Largura da pilha de $1.800 \mathrm{~mm}$ e espessura do separador de $20 \mathrm{~mm}$; (B) Largura da pilha de $1.800 \mathrm{~mm}$ e espessura do separador de $25 \mathrm{~mm}$; (C) Largura da pilha de $900 \mathrm{~mm}$ e espessura do separador de $20 \mathrm{~mm}$; (D) Largura da pilha de $900 \mathrm{~mm}$ e espessura do separador de $25 \mathrm{~mm}$.

Figure 1. Moisture loss over the days of air drying of Eucalyptus spp. wood for the different treatments evaluated. (A) Stack width of $1.800 \mathrm{~mm}$ and separator thickness of $20 \mathrm{~mm}$; (B) Stack width of $1.800 \mathrm{~mm}$ and separator thickness of $25 \mathrm{~mm}$; (C) Stack width of $900 \mathrm{~mm}$ and separator thickness of $20 \mathrm{~mm}$; (D) Stack width of $900 \mathrm{~mm}$ and separator thickness of $25 \mathrm{~mm}$. 
Stangerlin et al. (2009), avaliando o comportamento da secagem da madeira de Eucalyptus sp. em duas metodologias, encontraram umidade final para a madeira de Corymbia citriodora, E. saligna e E. tereticornis de $20,71 \%, 20,75 \%$ e $20,30 \%$, respectivamente, seca ao ar.

A cinética da pré-secagem (Tabela 3 ) segue uma tendência parabólica, em que o modelo de regressão parabólico que melhor se ajusta à espécie e às condições da pré-secagem foi [sqrt $\left.\left(\beta_{0}+\beta_{1}{ }^{*} \operatorname{sqrt}(\mathrm{X})\right)\right]$, em que se obtiveram valores de coeficientes de determinação $\left(R^{2}\right)$ considerados representativos, demonstrando correlação entre a perda de umidade ao longo do tempo.

Logo no início da secagem, há uma tendência linear, mas ao avaliar todo o ciclo da pré-secagem da madeira, há predominância de a perda de umidade ocorrer de forma parabólica, conforme estudos realizados por Siau (1995), Loiola (2015) e Loiola et al. (2015).

Na Tabela 4 constam os resultados referentes à umidade final da madeira de Eucalyptus spp., em função das diferentes pilhas confeccionadas.

Observa-se que as pilhas construídas com largura de $900 \mathrm{~mm}$ atingiram as menores umidades durante o tempo de pré-secagem e os menores coeficientes de variação $(8,73$ e 8,34, respectivamente, para a espessura do separador de 20 e com $25 \mathrm{~mm}$ ). Uma possível justificativa para essa homogeneidade entre a umidade final das tábuas pode ser as mesmas utilizadas para a discrepância entre a umidade final da madeira entre as pilhas com diferentes larguras: perda de eficiência da transferência de calor e de massa no fluxo de fluido (ar) ao longo da largura das pilhas (1.800 e $900 \mathrm{~mm}$, respectivamente). Outro fator relevante é a capacidade de o ar absorver moléculas de vapor d'água em uma dada temperatura (pressão de vapor saturado) em função da largura da pilha.

Com relação ao tempo ocorrido para a avaliação da pré-secagem, observa-se que as tábuas alocadas nas pilhas com largura de $900 \mathrm{~mm}$ (independentemente da espessura dos separadores), após 60 dias de secagem, apresentavam perda menos acentuada da umidade, $o$ que evidencia que a madeira de E. grandis já possui umidade próxima à umidade de equilíbrio da região (Massaranduba - SC).

Na sua produção habitual, a empresa utilizava separadores (tabiques) de $20 \mathrm{~mm}$ de espessura e largura das pilhas de $1.800 \mathrm{~mm}$, com tempo de pré-secagem de 150 dias. Esse ciclo de secagem utilizado pela empresa visava à minimização da umidade entre as tábuas nas pilhas. No processo de secagem convencional, essa

Tabela 3. Equações ajustadas para a estimativa da umidade ao longo dos dias da secagem ao ar da madeira de Eucalyptus spp. em função dos tratamentos avaliados.

Table 3. Adjusted equations for estimating the moisture over the days of air drying of Eucalyptus spp. according to the treatments evaluated.

\begin{tabular}{ccccccc}
$\begin{array}{c}\text { Largura da } \\
\text { pilha }(\mathbf{m m})\end{array}$ & $\begin{array}{c}\text { Espessura do } \\
\text { tabique }(\mathbf{m m})\end{array}$ & $\boldsymbol{\beta}_{\mathbf{0}}$ & $\boldsymbol{\beta}_{1}$ & $\mathbf{R}_{\text {aj }}$ & $\mathbf{s}_{\mathbf{y x}}(\%)$ & $\mathbf{F}$ \\
\hline 1800 & 20 & $9542,80^{*}$ & $-791,61^{*}$ & 84,3885 & 16,82 & $125,33^{\star}$ \\
1800 & 25 & $9518,66^{*}$ & $-809,02^{*}$ & 68,3376 & 20,13 & $50,64^{*}$ \\
\hline 900 & 20 & $14792,00^{*}$ & $-1737,01^{*}$ & 92,3290 & 26,60 & $277,83^{*}$ \\
900 & 25 & $10154,60^{*}$ & $-1146,87^{*}$ & 79,6449 & 23,76 & $90,99^{*}$ \\
\hline
\end{tabular}

"Significativo ao nível de $1 \%$ de significância $(\mathrm{p}>0,01)$. $\beta_{0}$ : coeficiente da regressão estimada; $\beta_{1}$ : coeficiente do tempo de secagem (dias); $\mathrm{R}_{\mathrm{a} \text {; }}^{2}$ coeficiente de determinação ajustado; $\mathrm{s}_{\mathrm{yx}}$ : erro-padrão da estimativa; $\mathrm{F}$ : fator de significância.

Tabela 4. Resultado da umidade final para a madeira de Eucalyptus spp. submetida à secagem ao ar.

Table 4. Results final moisture for Eucalyptus spp. subjected to air drying.

\begin{tabular}{ccc} 
& \multicolumn{2}{c}{$\begin{array}{c}\text { Umidade final da madeira (\%) } \\
\text { Largura da pilha }(\mathbf{m m})\end{array}$} \\
\cline { 2 - 3 } Espessura tabique $(\mathbf{m m})$ & $\mathbf{1 8 0 0}$ & $\mathbf{9 0 0}$ \\
& 41,70 & 20,69 \\
20 & $(14,52)(34,82)^{*}$ & $(1,81)(8,73)$ \\
25 & 35,46 & 19,97 \\
& $(20,49)(57,78)$ & $(1,67)(8,34)$ \\
\hline
\end{tabular}

*Valores entre parênteses correspondem ao desvio-padrão e ao coeficiente de variação, respectivamente. 
variação de umidade da madeira acarretava aumento dos custos operacionais e, principalmente, dificuldades no controle do processo, o que acarretava aumento do retrabalho em função da heterogeneidade da umidade após a secagem convencional.

A partir dos resultados da presente pesquisa, a empresa optou por adotar em seu processo produtivo pilhas com $900 \mathrm{~mm}$ de largura e separadores (tabiques) com $25 \mathrm{~mm}$ de espessura. Essa redução da largura da pilha de madeira para a pré-secagem reduziu a variação de umidade entre as tábuas dentro da pilha, possibilitando maior controle no processo de secagem convencional, reduzindo o ciclo de secagem e a minimização dos defeitos ocasionados pelo processo (rachaduras, empenamentos e colapso).

É importante mencionar que a redução da largura da pilha proporcionou redução do tempo de pré-secagem e homogeneização da umidade, além de reduzir o capital imobilizado e o custo de oportunidade pela empresa. Outra vantagem para a redução da largura da pilha é a movimentação das pilhas ao longo do pátio com redução do esforço exercido pelas empilhadeiras (redução da massa da pilha). No entanto, existem aspectos negativos a serem considerados, como aumento da área necessária de pátio, maior número de pilhas, além de maior mão de obra na construção das pilhas, mas deve-se sempre prezar pela qualidade da madeira, visando a seu maior aproveitamento dentro da indústria madeireira.

Quanto à análise de variância da taxa de secagem da madeira de E. grandis em função da largura da pilha e espessura dos tabiques, não houve diferença estatística para o fator espessura do separador (tabique), já o fator largura das pilhas foi significativo estatisticamente. No entanto, as interações entre a largura da pilha e a espessura do separador - tabique são apresentadas na Tabela 5.

Observa-se que a velocidade de secagem da madeira de E. grandis foi influenciada apenas pela largura da pilha de madeira, a qual diferiu estatisticamente ao nível de $5 \%$ de significância $\left(0,65 \%\right.$ e $\left.1,04 \% \mathrm{U} \mathrm{dia}^{-1}\right)$, respectivamente, para as pilhas com largura de 1.800 e $900 \mathrm{~mm}$, independentemente da espessura do separador (tabique).

Essa diferença da velocidade de secagem para as pilhas com larguras distintas representa, na prática, para um pátio de secagem contendo $50 \mathrm{~m}^{3}$ de madeira empilhada, uma evaporação média diária de $253 \mathrm{~kg}$ de água para uma velocidade de secagem de $1,04 \% \mathrm{U} \mathrm{dia}^{-1}$, enquanto a velocidade de secagem de $0,65 \% \mathrm{U} \mathrm{dia}^{-1}$ representa uma evaporação média diária de $158 \mathrm{~kg}$ de água.

Analisando os valores de taxa de secagem da madeira para cada tratamento avaliado, nota-se que as pilhas confeccionadas com largura de $1.800 \mathrm{~mm}$ tiveram

Tabela 5. Velocidade de secagem das madeiras de Eucalyptus spp. em função da largura da pilha e espessura dos separadores.

Table 5. Drying velocity of Eucalyptus spp. of wood an function the width the stack and thickness of the stickers wood.

\begin{tabular}{|c|c|c|c|}
\hline \multicolumn{4}{|c|}{ Velocidade de secagem $\left(\% \mathrm{U} \mathrm{dia}^{-1}\right)$} \\
\hline \multirow{3}{*}{ Largura* } & \multicolumn{3}{|c|}{ Largura da pilha (mm) } \\
\hline & 1800 & \multicolumn{2}{|c|}{900} \\
\hline & $0,65 b$ & \multicolumn{2}{|c|}{$1,04 \mathrm{a}$} \\
\hline \multirow{3}{*}{ Espessura $^{\text {ns }}$} & \multicolumn{3}{|c|}{ Espessura do tabique (mm) } \\
\hline & 20 & \multicolumn{2}{|c|}{25} \\
\hline & 0,88 & \multicolumn{2}{|c|}{0,82} \\
\hline \multirow{4}{*}{ Largura $\times$ espessura ${ }^{\text {ns }}$} & \multirow{2}{*}{ Espessura do tabique ( $\mathrm{mm}$ ) } & \multicolumn{2}{|c|}{ Largura da pilha (mm) } \\
\hline & & 1800 & 900 \\
\hline & 20 & $\begin{array}{c}0,62 \\
(0,16 ; 26,04)\end{array}$ & $\begin{array}{c}1,14 \\
(0,13 ; 11,85)\end{array}$ \\
\hline & 25 & $\begin{array}{c}0,69 \\
(0,23 ; 33,05)\end{array}$ & $\begin{array}{c}0,94 \\
(0,22 ; 23,69)\end{array}$ \\
\hline
\end{tabular}

${ }^{*}$ Significativo ao nível de $1 \%$ de probabilidade $(\mathrm{p}<0,01)$; ${ }^{\text {ns }}$ não significativo $(\mathrm{p}>0,05)$. As médias seguidas pela mesma letra, minúscula na horizontal, não diferem entre si (Tukey, $\mathrm{p}>0,05$ ). Os valores entre parênteses correspondem ao coeficiente de variação (\%) e ao desvio-padrão, respectivamente. 
valores de 0,62 e $0,69 \% \cdot \mathrm{dia}^{-1}$ (respectivamente, para os separadores com espessura de 20 e com $25 \mathrm{~mm}$ ), sendo inferiores aos das madeiras pertencentes às pilhas de $900 \mathrm{~mm}$ de largura $\left(1,14 \%\right.$ e $0,94 \% \mathrm{U} \mathrm{dia}^{-1}$, respectivamente, para os separadores com espessura de 20 e com $25 \mathrm{~mm}$ ).

Nota-se que a taxa de secagem da madeira alocada nas pilhas de $900 \mathrm{~mm}$ de largura foi $45 \%$ e $27 \%$ superior à da madeira alocada nas pilhas com largura de $1.800 \mathrm{~mm}$ (respectivamente, para os separadores com espessura de 20 e com $25 \mathrm{~mm}$ ), correspondendo, portanto, a um aumento na velocidade de secagem de $37,5 \%$, além de melhorar a distribuição da umidade na pilha, contribuindo para uma secagem convencional com maior qualidade e maior produtividade.

Realizando a estimativa do tempo de secagem conforme a metodologia proposta por Galvão \& Jankowsky (1985) para $20 \%$ de umidade final, as pilhas com $900 \mathrm{~mm}$ de largura necessitariam de 72 dias para atingir a umidade final desejada, enquanto as pilhas construídas com $1.800 \mathrm{~mm}$ de largura demandariam 115 dias, respectivamente.
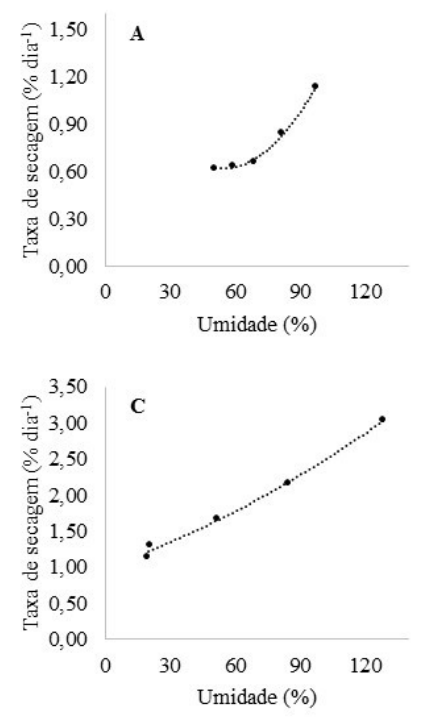

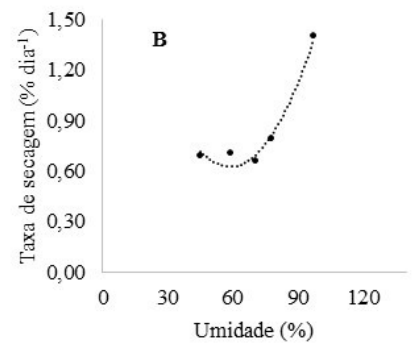

Os valores encontrados nesse trabalho foram superiores aos encontrados por Stangerlin et al. (2009) para as madeiras de E. citriodora e E. tereticornis $\left(0,68 \%\right.$ e $\left.0,51 \% \mathrm{U} \mathrm{dia}^{-1}\right)$, porém inferiores aos verificados para a madeira de E. saligna, onde os autores encontraram taxa de secagem de $1,66 \% \mathrm{U} \mathrm{dia}{ }^{-1}$, para pilhas com larguras menores.

A finalidade da pré-secagem é a remoção da água capilar da madeira e, consequentemente, a redução do ciclo de secagem em câmara convencional, proporcionando maior rotatividade de matériaprima para o empreendimento. Batista et al. (2010) comprovam a dificuldade de remoção da água de difusão da madeira do gênero Eucalyptus. Em seus estudos, para a madeira de E. saligna, E. grandis e E. dunnii, a velocidade de remoção da água capilar foi de 60,5421, 62,9393 e 65,6627\%, respectivamente, maior que a velocidade de remoção da água de difusão.

Observa-se que, na fase inicial, na taxa de secagem para todos os tratamentos avaliados (Figura 2) houve uma queda acentuada, resultado da movimentação da água livre presente na madeira sem impedimento.

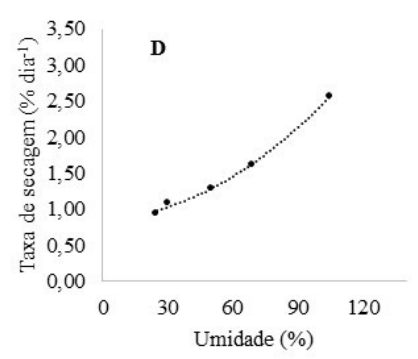

Figura 2. Comportamento da taxa de secagem das madeiras de Eucalyptus spp. em função da largura da pilha e da espessura dos tabiques. (A) Largura da pilha de $1.800 \mathrm{~mm}$ e espessura do separador de $20 \mathrm{~mm}$; (B) Largura da pilha de $1.800 \mathrm{~mm}$ e espessura do separador de $25 \mathrm{~mm}$; (C) Largura da pilha de $900 \mathrm{~mm}$ e espessura do separador de $20 \mathrm{~mm}$; (D) Largura da pilha de $900 \mathrm{~mm}$ e espessura do separador de $25 \mathrm{~mm}$.

Figure 2. Behavior drying rate of Eucalyptus spp. wood in the width and thickness of the stickers. (A) Stack width of $1.800 \mathrm{~mm}$ and separator thickness of $20 \mathrm{~mm}$; (B) Stack width of $1.800 \mathrm{~mm}$ and separator thickness of $25 \mathrm{~mm}$; (C) Stack width of $900 \mathrm{~mm}$ and separator thickness of $20 \mathrm{~mm}$; (D) Stack width of $900 \mathrm{~mm}$ and separator thickness of $25 \mathrm{~mm}$. 
Isso se justifica pelo fato de que o fenômeno de transferência de massa no início da secagem ocorre pelas cavidades celulares dos elementos vasculares da madeira e por evaporação, uma vez que é mantida na madeira por forças capilares muito fracas. Loiola et al. (2015) ainda relata que a velocidade de secagem é influenciada por uma série de fatores relacionados com a própria madeira, com a pilha e sua distribuição no pátio e com as condições climáticas.

\subsection{Avaliação dos defeitos antes e após a pré-secagem}

Na Tabela 6, encontram-se os resultados dos defeitos ocasionados pela pré-secagem da madeira de Eucalyptus spp. em função da largura da pilha e da espessura dos separadores (tabiques).

Para as rachaduras de topo, observa-se que a redução da largura das pilhas ocasionou aumento do índice de rachadura de topo (IRT). Esse aumento pode ter sido ocasionado em função da maior velocidade de secagem da madeira pertencente às pilhas confeccionadas em menor largura e com a menor umidade final das tábuas. Esses fatores interligados ocasionaram um aumento gradiente de umidade nas regiões contíguas da madeira, fazendo com que as fibras de madeira mais externas atingissem umidade menor do que a das fibras mais internas, gerando tensões de secagem, consequentemente ocasionando as rachaduras de topo (Marchesan et al., 2015). No entanto, o valor médio de IRT $(0,66 \%)$ pode ser considerado baixo.

Já em relação aos defeitos de arqueamento, nota-se que os valores obtidos em função da largura da pilha e espessura dos separadores (tabiques) podem ser considerados baixos $\left(0,97,0,83,0,27\right.$ e $0,83 \mathrm{~mm} \cdot \mathrm{m}^{-1}$, respectivamente, para os tratamentos $\mathrm{T} 1, \mathrm{~T} 2, \mathrm{~T} 3 \mathrm{e} \mathrm{T} 4)$.

Souza et al. (2012) relatam que a manifestação de peças arqueadas ao final da secagem é um dos defeitos mais problemáticos com relação ao seu controle, uma vez que durante a secagem as tábuas ficam dispostas sem

Tabela 6. Defeitos da madeira de Eucalyptus spp. após a secagem ao ar.

Table 6. Defects of Eucalyptus spp. after air drying.

\begin{tabular}{|c|c|c|c|c|c|c|}
\hline \multirow{2}{*}{$\begin{array}{l}\text { Largura da } \\
\text { pilha }(\mathrm{mm})\end{array}$} & \multirow{2}{*}{$\begin{array}{l}\text { Espessura do } \\
\text { tabique (mm) }\end{array}$} & \multicolumn{2}{|c|}{ Após desdobro } & \multicolumn{2}{|c|}{ Após secagem } & \multirow{2}{*}{$\begin{array}{l}\text { Diferença do } \\
\text { IRT (\%) }\end{array}$} \\
\hline & & \multicolumn{2}{|c|}{ IRT médio (\%) } & \multicolumn{2}{|c|}{ IRT médio (\%) } & \\
\hline 1800 & 20 & \multicolumn{2}{|c|}{3,46} & \multicolumn{2}{|c|}{3,69} & 0,23 \\
\hline 1800 & 25 & \multicolumn{2}{|c|}{1,65} & \multicolumn{2}{|c|}{1,78} & 0,13 \\
\hline 900 & 20 & \multicolumn{2}{|c|}{8,83} & \multicolumn{2}{|c|}{9,56} & 0,73 \\
\hline 900 & 25 & \multicolumn{2}{|c|}{5,53} & \multicolumn{2}{|c|}{6,11} & 0,59 \\
\hline \multirow{3}{*}{$\begin{array}{c}\text { Largura da } \\
\text { pilha } \\
\text { (mm) }\end{array}$} & \multirow{3}{*}{$\begin{array}{l}\text { Espessura } \\
\text { do tabique } \\
(\mathrm{mm})\end{array}$} & \multicolumn{2}{|c|}{ Após desdobro } & \multicolumn{2}{|c|}{ Após secagem } & \multirow{3}{*}{$\begin{array}{l}\text { Diferença do } \\
\text { arqueamento } \\
\left(\mathbf{m m} \cdot \mathbf{m}^{-1}\right)\end{array}$} \\
\hline & & \multicolumn{2}{|c|}{ Arqueamento } & \multicolumn{2}{|c|}{ Arqueamento } & \\
\hline & & $\left(\mathrm{mm} \cdot \mathrm{m}^{-1}\right)$ & $\%$ & $\left(\mathrm{~mm} \cdot \mathrm{m}^{-1}\right)$ & $\%$ & \\
\hline 1800 & 20 & 0,97 & 0,10 & 1,94 & 0,19 & 0,97 \\
\hline 1800 & 25 & 1,11 & 0,11 & 1,94 & 0,19 & 0,83 \\
\hline 900 & 20 & 3,06 & 0,31 & 3,33 & 0,33 & 0,27 \\
\hline 900 & 25 & 3,61 & 0,36 & 4,44 & 0,44 & 0,83 \\
\hline \multirow{3}{*}{$\begin{array}{c}\text { Largura da } \\
\text { pilha } \\
\text { (mm) }\end{array}$} & \multirow{3}{*}{$\begin{array}{c}\text { Espessura } \\
\text { do tabique } \\
(\mathrm{mm})\end{array}$} & \multicolumn{2}{|c|}{ Após desdobro } & \multicolumn{2}{|c|}{ Após secagem } & \multirow{3}{*}{$\begin{array}{c}\text { Diferença do } \\
\text { encurvamento } \\
\left(\mathbf{m m} \cdot \mathbf{m}^{-1}\right)\end{array}$} \\
\hline & & \multicolumn{2}{|c|}{ Encurvamento } & \multicolumn{2}{|c|}{ Encurvamento } & \\
\hline & & $\left(\mathrm{mm} \cdot \mathrm{m}^{-1}\right)$ & $\%$ & $\left(\mathrm{~mm} \cdot \mathrm{m}^{-1}\right)$ & $\%$ & \\
\hline 1800 & 20 & 2,50 & 0,25 & 4,86 & 0,49 & 2,39 \\
\hline 1800 & 25 & 4,72 & 0,47 & 8,06 & 0,81 & 3,34 \\
\hline 900 & 20 & 10,56 & 1,06 & 14,17 & 1,42 & 3,61 \\
\hline 900 & 25 & 9,72 & 0,97 & 12,50 & 1,25 & 2,78 \\
\hline \multirow{3}{*}{$\begin{array}{l}\text { Largura da } \\
\text { pilha } \\
(\mathrm{mm})\end{array}$} & \multirow{3}{*}{$\begin{array}{c}\text { Espessura } \\
\text { do tabique } \\
(\mathrm{mm})\end{array}$} & \multicolumn{2}{|c|}{ Após desdobro } & Após & & Diferença do \\
\hline & & Enca & & Encan & nto & encanoamento \\
\hline & & $\left(\mathrm{mm} \cdot \mathrm{m}^{-1}\right)$ & $\%$ & $\left(\mathrm{~mm} \cdot \mathrm{m}^{-1}\right)$ & $\%$ & $\left(\mathbf{m m} \cdot \mathbf{m}^{-1}\right)$ \\
\hline 1800 & 20 & 0,14 & 0,01 & 1,11 & 0,11 & 0,97 \\
\hline 1800 & 25 & 0,14 & 0,01 & 0,69 & 0,07 & 0,55 \\
\hline 900 & 20 & 0,00 & 0,00 & 2,50 & 0,25 & 0,25 \\
\hline 900 & 25 & 0,28 & 0,03 & 3,06 & 0,31 & 2,78 \\
\hline
\end{tabular}

IRT: índice de rachadura de topo. 
qualquer restrição lateral que as impeça de se deformarem. Lumley \& Choong (1981) ainda complementam que a presença de peças empenadas, nesse caso em especial o arqueamento, com as rachaduras, é o principal defeito incidente na madeira seca ao ar livre.

Entretanto, a maior flecha $\left(0,97 \mathrm{~mm} \cdot \mathrm{m}^{-1}\right)$ foi obtida para a secagem que ocorreu de forma mais lenta. Os principais motivos para a incidência desse defeito são a proporção de lenhos juvenil e adulto na mesma peça de madeira e o modelo de desdobro utilizado, visto que tábuas radiais possuem propensões à incidência desse defeito.

Os índices de arqueamento obtidos neste trabalho para todos os tratamentos avaliados foram inferiores ao limite preconizado pela NBR 14806 - Madeira Serrada de Eucalipto (ABNT, 2002), o qual é de $5 \mathrm{~mm} \cdot \mathrm{m}^{-1}$.

Para o defeito de encurvamento ocasionado na secagem ao ar, os valores obtidos foram inferiores ao limite preconizado pela NBR 14806 (ABNT, 2002), o qual é de $5 \mathrm{~mm} \mathrm{~m}^{-1}$. Chen \& Rosen (1979) e Stangerlin et al. (2009), avaliando duas metodologias de secagem, também encontraram valores de encurvamento semelhantes aos deste trabalho, assim como Rocha \& Tomaselli (2002).

Simpson (1991) afirmou que o encurvamento não é um defeito problemático na madeira, uma vez que pode ser facilmente eliminado durante o processo de empilhamento da carga de madeira. De modo geral, o encurvamento é influenciado muito mais pelo método de empilhamento do que pelas circunstâncias de secagem. Mediante a adição de pesos sobre a pilha e/ou colocação de peças defeituosas na parte de baixo desta, conforme realizado nesse estudo, possibilita-se a redução significativa do encurvamento (Bekele, 1995).

Para o encanoamento, a pré-secagem ocasionou esse tipo de defeito nas magnitudes de 0,97, 0,55, 0,25 e 2,78 ( $\left.\mathrm{mm} \cdot \mathrm{m}^{-1}\right)$, respectivamente, para os tratamentos T1, T2, T3 e T4. De acordo com Galvão \& Jankowsky (1985) e Batista et al. (2015), o encanoamento pode ser resultante da diferença entre as retrações transversais, pela exposição de apenas uma face da tábua à secagem, assim como da utilização de peças tangenciais que são naturalmente mais propensas a esse tipo de empenamento do que as radiais.

No entanto, o correto empilhamento, dispondo-se as peças tangenciais na parte de baixo da carga, a utilização de tábuas excedentes, com função de restrição mecânica, e a secagem lenta e uniforme proporcionaram a ausência desse defeito nas duas metodologias de secagem.

\section{CONCLUSÕES}

A redução da largura da pilha de madeira aumentou a velocidade de secagem da madeira de E. grandis, reduzindo o tempo de permanência da madeira no pátio de secagem.

A redução da largura da pilha reduziu a umidade final das tábuas e a variação de umidade entre as tábuas, favorecendo o controle do processo.

A redução da largura das pilhas não afetou a qualidade da madeira de Eucalyptus spp., sendo as predições da qualidade avaliada inferiores aos limites preconizados pela norma, podendo ser classificados como leves.

\section{STATUS DA SUBMISSÃO}

Recebido: 22 jul., 2014

Aceito: 26 jun., 2016

\section{AUTOR(ES) PARA CORRESPONDÊNCIA}

\section{Linéia Roberta Zen}

Departamento de Engenharia e Tecnologia Florestal, Universidade Federal do Paraná UFPR, Curitiba, PR, Brasil e-mail: lizenflorestal@gmail.com

\section{REFERENCIAS}

Associação Brasileira de Normas Técnicas - ABNT. NBR14806: madeira serrada de eucalipto. Rio de Janeiro; 2002.

Associação Brasileira de Normas Técnicas - ABNT. NBR7190: projeto de estruturas de madeira - determinação das propriedades das madeiras para projetos de estruturas. Rio de Janeiro; 1997.

Batista DC, Klitzke RJ, Rocha MP, Muñiz GIB, Batista TR. Volume loss as a tool to assess kiln drying of Eucalyptus wood. Floresta e Ambiente 2013; 20(2): 250-256. http:// dx.doi.org/10.4322/floram.2013.017.

Batista DC, Klitzke RJ, Rocha MP. Qualidade da secagem convencional conjunta da madeira de clones de três espécies de Eucalyptus sp. Ciência Florestal 2015; 25(3): 711-719. http://dx.doi.org/10.5902/1980509819621.

Batista DC, Klitzke RJ, Santos CVT. Densidade básica e retratibilidade da madeira de clones de três espécies de Eucalyptus. Ciência Florestal 2010; 20(4): 665-674. http:// dx.doi.org/10.5902/198050982425. 
Bauer K. Development and optimisation of a low-temperature drying schedule for Eucalyptus grandis (Hill) ex Maiden in a solar-assisted timber dryer [thesis]. Hohenheim: Fakultät Agrarwissenschaften der Universität Hohenheim; 2003.

Bekele T. Degradation of boards of Eucalyptus globulus Labill. and Eucalyptus camaldulensis Dehnh. during air drying. Holz als Roh- und Werkstoff 1995; 53(6): 407-412. http://dx.doi.org/10.1007/s001070050120.

Campbell GS, Hartley J. Drying and dried wood. In: Hillis WE, Brown AG, editores. Eucalyptus for wood production. Melbourne: Academic Press; 1988.

Chen PYS, Rosen HN. Drying yellow-poplar in a highly efficient solar kiln. In: Proceedings of 30th Annual Western Dry Kiln Clubs; 1979; Coeur d'Alene. Idaho; 1979. p. 23-32.

Galvão APM, Jankowsky IP. Secagem racional da madeira. 1. ed. Nobel: São Paulo; 1985.

Klitzke RJ. Secagem da madeira. In: Oliveira JTS, editor. Tecnologias aplicadas ao setor madeireiro. Visconde do Rio Branco: Suprema Gráfica e Editora Ltda; 2007.

Loiola PL, Juizo CGF, Marchesan R, Klitzke RJ, Rocha MP. Drying of wood from Mimosa scabrella, Eucalyptus dunnii and Tectona grandis in solar kiln, in south Brazil. Australian Journal of Basic and Applied Sciences 2015; 9(5): 445-453.

Loiola PL. Secagem convencional da madeira de teca (Tectona grandis L.f.) sob diferentes condições [dissertação]. Curitiba: Setor de Ciências Agrárias. Universidade Federal do Paraná; 2015.

Lumley TG, Choong ET. Solar drying of wood in Louisiana. Baton Rouge: Louisiana State University and Agricultural and Mechanical College; 1981. 55 p.

Marchesan R, Loiola PL, Tecchio MM, Juizo CGF, Rocha MP, Klitzke RJ. Avaliação das técnicas de anelamento e inserção de sabre em plantios de Eucalyptus grandis visando a qualidade da madeira serrada. Revista Científica Eletrônica de Engenharia Florestal 2015; 45(4): 695-704.

Northway RL. Drying strategies for plantation-grown eucalypts. In: Proceedings International iufro wood drying conference; 1996; Quebec. Quebec: IUFRO; 1996. p. 289-296.

Paes JB, Loiola PL, Oliveira JTS, Braz RL, Klitzke RJ. Efeito de soluções salinas na estabilidade dimensional das madeiras de Corymbia tolleriana e Eucalyptus cloeziana. Scientia Forestalis 2015; 43(106): 105-125.

Ponce RH, Watai LT. Secagem da madeira. Brasília: Instituto de Pesquisa Tecnológica; 1985.

Rocha MP, Tomaselli I. Efeito do modelo de desdobro na qualidade da madeira serrada de Eucalyptus grandis E Eucalyptus dunnii. Cerne 2002; 8(2): 70-83

Siau JF. Wood: influence of moisture on physical properties. Blacksburg: Virginia Polytechnic Institute and State University. Department of Wood Science and Forest Products; 1995.227 p.

Simpson WT. Dry kiln operator's manual. Madison: U.S. Department of Agriculture; 1991. 274 p.

Souza JT, Trevisan R, Denardi L, Stangerlin DM, Vivian MA, Haselein CR et al. Qualidade da madeira serrada proveniente de árvores dominantes e médias de Eucalyptus grandis submetidas à secagem. Cerne 2012; 18(1): 167-174. http://dx.doi.org/10.1590/S0104-77602012000100020.

Stangerlin DM, Santini EJ, Susin F, Melo RR, Gatto DA, Haselein CR. Uso de estufa solar para secagem de madeira serrada. Ciência Florestal 2009; 19(4): 461-472. http:// dx.doi.org/10.5902/19805098900.

Stöhr HP. The seasoning of South African grown Eucalyptus grandis and Eucalyptus saligna. South African Forestry Journal 1977; 102(1): 61-66. 